\title{
An analysis of multimodal resources in environmental protection posters
}

\author{
Ruswan Dallyono* and Didi Sukyadi \\ Department of English Education, Faculty of Language and Literature Education, Universitas Pendidikan Indonesia, \\ Jl. Dr. Setiabudhi No. 229 Bandung, West Java, Indonesia
}

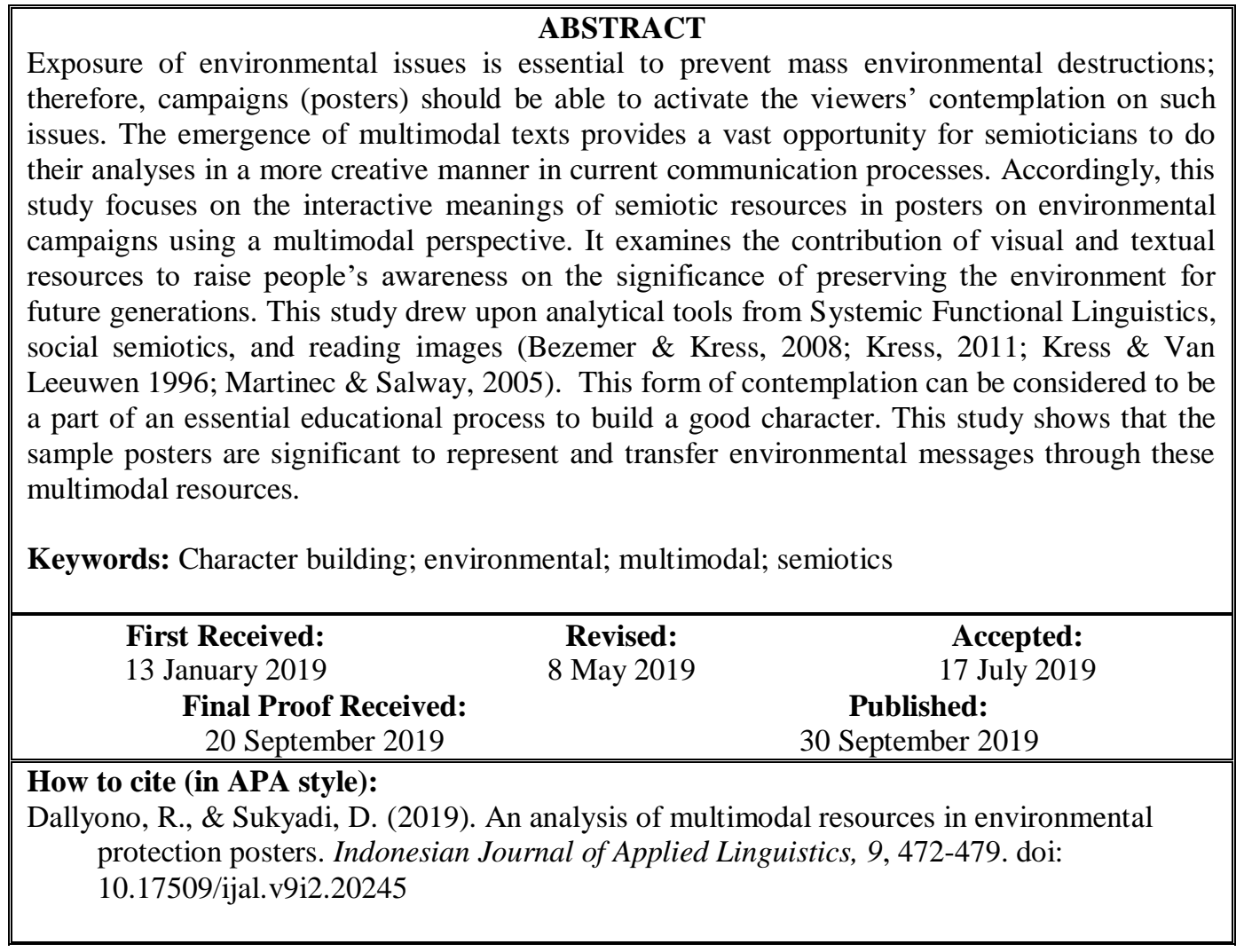

\section{INTRODUCTION}

Currently, the earth is facing many disheartening environmental issues as a result of modern life and industrialization. Today's environmental issues, such as loss of biodiversity, air pollution, and global warming are affecting each and every human, animal and vegetation on this planet. Sadly, the degradation of the natural environment is now occurring at an alarming rate with an unprecedented level.

To cope with the situation, campaigns against the lack of awareness of this environmental degradation are being intensified through a broad range of electronic, print, and online media worldwide. In general, these campaigns are directed to promoting environmental sustainability. At any rate, it is expected that people's need for resources should be met without jeopardizing the ability of the future generation to maintain their supply of resources. Without the implementation of environmental sustainability actions, long-term viability cannot be guaranteed.

Education is a key aspect to promoting environmental sustainability. It plays a central role in processes that can accelerate social change and climate change mitigation (Ledley \& Rooney-Varga, 2017). Making people aware of the issues is part of an essential educational practice as the awareness of environmental issues requires a mind-set change on the part of the people. It starts from every individual's thinking system. Such a thinking system represents one's character. An individual's character is that person's collection of character traits as relatively stable dispositions to think, feel, and behave in certain ways in certain situations (Webber, 2006). 
As a medium of mass communication, both online and offline posters are considered to be attractive due to their design by combining texts and images in a cohesive manner. Both texts and images complement one another in conveying messages. This new perspective is a result of the rapid development of technology which has contributed to the birth of multimedia language (Wang, 2015). Images function as the decorative or the supportive function to verbal text implies that meanings are related to the verbal text. Images have a myriad of possible meanings, therefore the verbal has to come to the rescue of 'fixing' or 'stabilising' their meanings (Barthes, 1967). The use of text and image results in relative effectiveness of some posters compared to other media such as newsletters. Apparently, multimodal (the use of several modes to deliver messages) resources enable image and text to enter the communicational landscape in new and significant manners (Jewit, 2009, p. 18).

Against such a background, this study is an attempt to analyze how the use of multimodal resources represents the concept of environmental sustainability. Some of the relevant literature is discussed initially to provide context to the study. In communicating messages, campaign posters require more than just linguistic forms. In fact, nonverbal communication has been taken as a potential topic in understanding language practice (Birdwhistell, 1952; Goffman, 1959; Hall, 1959; Ruesch \& Bateson, 1951; Pike, 1954). Prior to the social semiotic theory of multimodality, these studies serve an underrated topic about non-linguistic modes of communication.

The use of multimodal resources in posters has been particularly indispensable for information distribution these days. In fact, there has been extensive research on the use of multimodality in the fields of education, communication, and graphic designs so far. These studies vary in the use of data, objectives, and methods. Sipe (1998), for instance, examined how texts synergize with pictures in creating the meaning of the narrative in delivering messages. The study focuses on the significance of the verbal and the visual texts as media to communicate messages to the readers.

Meanwhile, Mavers (2004) explored how multimodal texts can be understood by examining what the semiotic resources of graphic representation are, how they carry meaning and how they interrelate in educational posters. Torr (2004) and Tulk (2005) concluded that the use of multimodal resources is considered to improve the development of children's literacy in their class. Howe (2009) examined the role of education in conserving the natural environment and sustainable development. Williams (2017) assessed the levels of environmental literacy among high school students and investigated factors that affected their literacy levels. Bedi (2019) investigated on the use of multimodality in a film poster as a crucial strategy for advertising and apprising the general public of a film. Thus, the multimodality of graphic representational designs in educational posters has significant implications for pedagogy, curriculum policy, professional development, and the research community.

Based on our online and offline searches, studies on multimodality, in terms of literacy improvement and environmental protection in posters, are limited. The integration of multimodality into literacy improvement and natural environmental protection is crucial to analyze as, nowadays, environmental messages are delivered not only through verbal, but also visual representation. The reason is that visual representation is a supportive element of verbal mode to strengthen the messages. The present study drew upon semiotics to analyze the integration between multimodal resources (to represent and transfer environmental messages) and literacy improvement by combining tools, namely SFL and logico-semantic relations (Martinec \& Salway, 2005).

\section{METHOD}

Data for this study were collected from mostly from World Wide Fund for Nature (WWF) campaign posters published on various websites as listed in table 1.

Table 1. Sources of the posters

\begin{tabular}{ll}
\hline \multicolumn{1}{c}{ Figures } & \multicolumn{1}{c}{ Websites } \\
\hline Figure 1 & https://www.trendhunter.com/amp/trends/manfish-wwf \\
\hline Figure 2 & https://www.adsoftheworld.com/media/print/wwf_panda_3 \\
\hline Figure 3 & https://www.denverwater.org/about-us/history/use-only-what-you-need \\
\hline Figure 4 & https://www.adsoftheworld.com/media/print/wwf_extinction_cant_be_fixed_rhino \\
\hline Figure 5 & https://www.adsoftheworld.com/media/print/tarzan_0 \\
\hline
\end{tabular}

Five environmental posters were purposively selected to be analyzed by using a social semiotic method of Bezemer and Kress (2008) as the framework of analysis. Social semiotics focuses on social meaningmaking practices of all types, whether visual and verbal. Therefore, this study focuses not only on the verbal mode of posters, but also its relation to their visual representation to convey environmental messages.

In order to come up with clear interactional meanings between multimodal resources, this study is concerned with what is represented verbally and visually in posters rather than existing connections of text-reader/viewer. In reality, posters can be used by anybody to put their messages out; however, their perspective is never free from social constraints. Therefore, it is the task of this study to theorize the relationship of each mode in conceptualizing environmental sustainability.

Under the framework of a qualitative method, this study used SFL, Social Semiotics, Reading Images 
(Bezemer \& Kress, 2008; Kress, 2011; Kress \& Van Leeuwen, 1996; Martinec \& Salway, 2005). Each poster, firstly, was divided into three major concepts of visual mode (contact, social distance, and attitude). After that, the relationships between images and texts were analyzed by using the logico-semantic theory (Martinec \& Salway, 2005). The theory is mainly about the relation between clauses in terms of logicosemantics. In the present study, the posters were analyzed by considering two board kinds, namely expansion (extension, enhancement, and elaboration) and projection (locution and idea).

The apprehension of both aspects (text-image) is a fundamental element to initiate a paradigm shift from individual understanding to societal change. The individual thinking system can be directed by a set of contextual topics. Therefore, the analysis attempts to reveal the potential power of multimodal resources used in the posters to represent messages pertaining to environmental education.

\section{FINDINGS}

The findings begin with the results of transitivity and mood analysis of the verbal text in SFL concepts as proposed by Halliday (1994). It is then followed by the results of the analysis conducted on the visual text of the posters. The following table summarizes the transitivity analysis.

Table 2. Types of processes found in the posters

\begin{tabular}{clc}
\hline Poster & \multicolumn{1}{c}{ Verbal text } & Process \\
\hline 1 & Stop climate change before it changes you. & Material \\
2 & - & - \\
3 & "Would you care more if I was a panda?" & Mental \\
4 & Use only what you need. & Material \\
5 & Extinction can't be fixed & Material \\
\hline
\end{tabular}

The transitivity analysis of verbal texts in the posters indicates that the messages were mostly constructed and represented through the use of material processes (3) and mental process (1). Poster 2 has no verbal text meaning that messages are only transferred by visual representation.

The material process is a process of doing or happening, and the Actor is the key participant. Three verbal texts on three posters used material processes. This fact shows that the readers (represented by the use of 'you' in poster 1 and 4) are the actor of the issues. On poster 5 , the actor is deleted as the verbal text is in a passive form; therefore, the goal is positioned as the initial part of the text. Poster 3 represents the message by using mental process. Mental process has two participants (senser and phenomenon). The senser of the verbal text on poster 3 is the reader (you), the phenomenon is panda.

In poster 1 , it is discernible that, at first glance, a mutant man (a human-fish) is the central point of this visual media. The visual object is supported by a verbal expression "stop climate change before it changes you". The analysis shows that the image is put in photo size and the focus of the image is sharp. It can be inferred that the object is easy to comprehend. In other words, viewers will not have an alternative reference of the object. The object's appearance is a posture. In this sense, the image exhibits shoulders, a neck, a chest, and a fish face. The man is wearing a blue shirt and placed at the centre of the poster. Generally, the main colour of the poster is dark by giving slightly colour to the man's outfit.

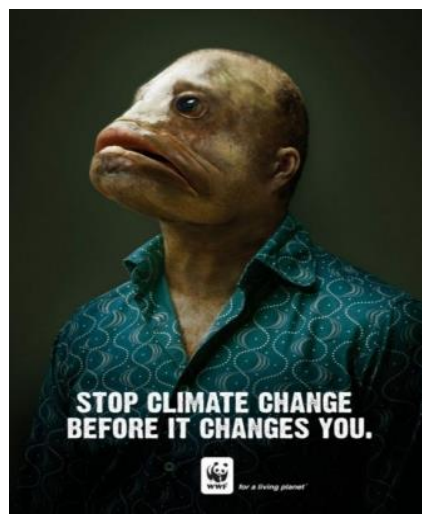

Figure 1. Transactional monologic image act on Poster 1

(Source: https://www.trendhunter.com/amp/trends/manfish-wwf)

The image gazes indirectly. This gaze does not generate a vector between the eye lines of the viewers. As the represented object does not look directly at the viewers but gaze away, it can be considered as an offer.
The poster is trying to 'offer' something. Kress and Van Leeuwen (1996) theorize what is meant by 'image act' to the system of 'speech act' and 'person' in language. In this specific context, according to Halliday (2001), 
'offer' is realized by offering information. The information will initiate the interactivity of text-image relationship. Compared to daily interaction, with its flexible shifts of different modes, the verbiage of figure
1 is monologic. Each word works the same way to offer information for viewers. Therefore, when this study aims to examine the contribution of the text to interpersonal aspect, it is compulsory to look elsewhere.

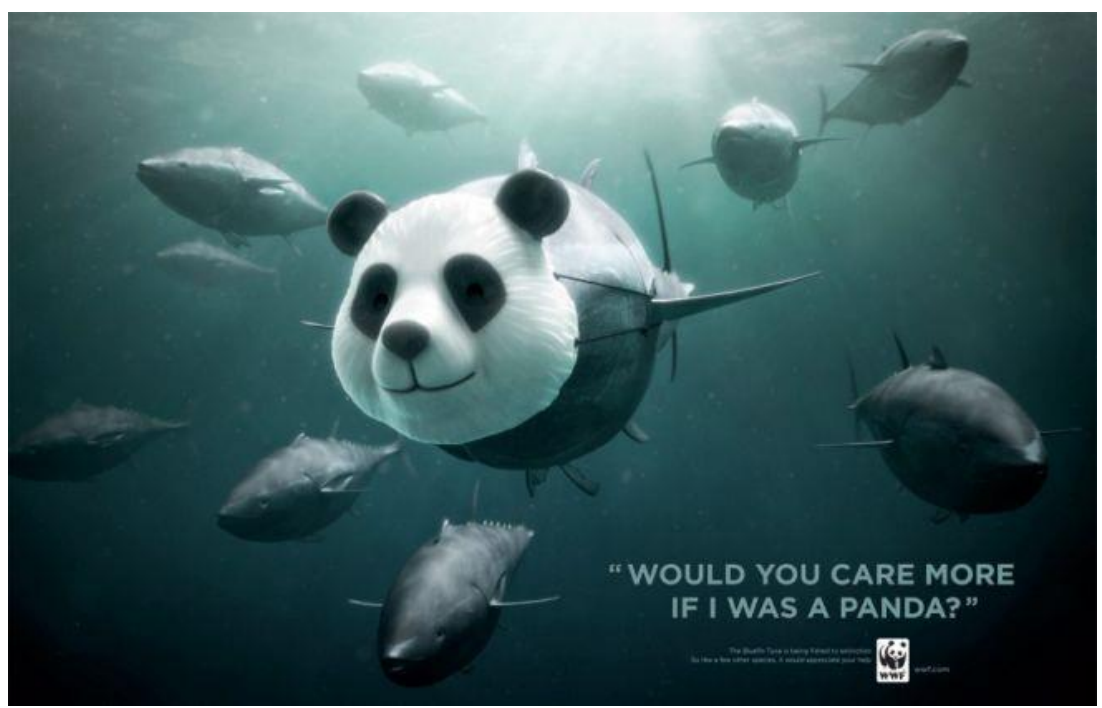

Figure 2. Theme-focus in conditional formula on Poster 3

(source: https://www.adsoftheworld.com/media/print/wwf_panda_3)

In relation to the pattern of 'theme' and 'focus', it is more interesting as it uncovers some facts. It is started by the use of modal verb 'will' followed by mental process 'care'. It reflects that the attitude of the text is 'affect' as, from speaker-oriented, the viewers are encouraged to do thing with emotional (mental) responses on the issues. Moreover, the focus of the text is initiated by the use of relational process. In this sense, the viewers need to think about the ethical evaluation of their unequal care on the 'reality' presented by its relational process. Therefore, the value of this expression is affect-judgement. Furthermore, the value is positive-inscribed. The reason is that there is an evaluative noun 'panda' in relational process. There is no figurative nuance, but the issue is strictly referred to unequal comparison between care about fish and panda. The reality is represented, not by implicit manner, by the conditional question formula.

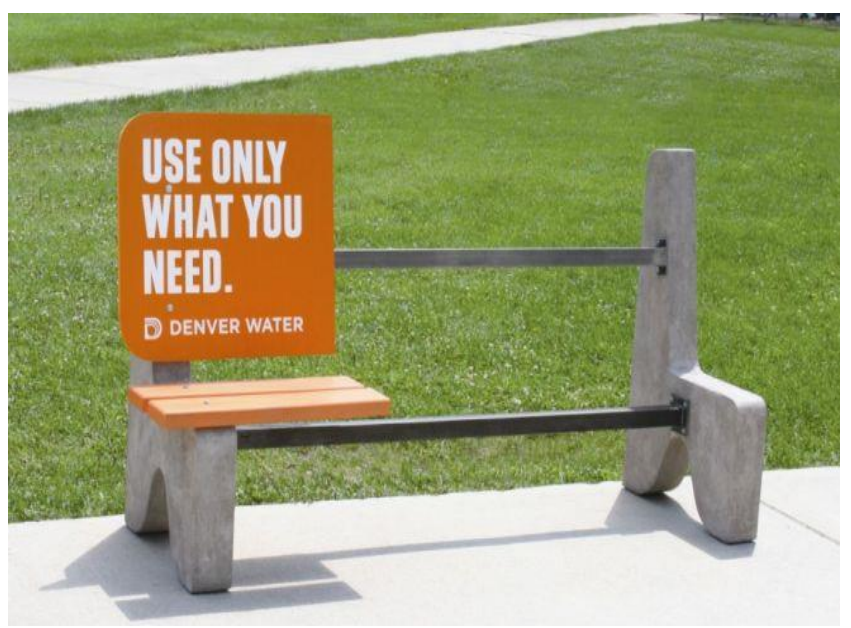

Figure 3. The absence of gaze on living object on poster 4

(source: https://www.denverwater.org/about-us/history/use-only-what-you-need)

Figure 3 indicates that the image is placed in photo size. The focus of the image is sharp. It is easy to identify that the object is a bench with half-removed of its major part. The visual representation is colourful, so that it represents more than one colour in the poster. There is no, to be noticed, living object to see.
Therefore, it is not relevant to talk about contact produced by gazing of a living object. It is more relevant to analyze the contact based on the object itself.

A bench, as an object, consists of given and new information. It can be identified that the given information is initially a complete bench. The 
assumption beyond the information is that bench condition is well-structured at first, but for some reason, it needs to be cut down. To deeply comprehend the context, it may be necessary to scrutinize a dichotomy between the backgrounds (green golf course) and foreground (half-removed bench). This research identifies the background as a representation of high consumption of water. The foreground, in contrary, represents the reduction of water consumption.

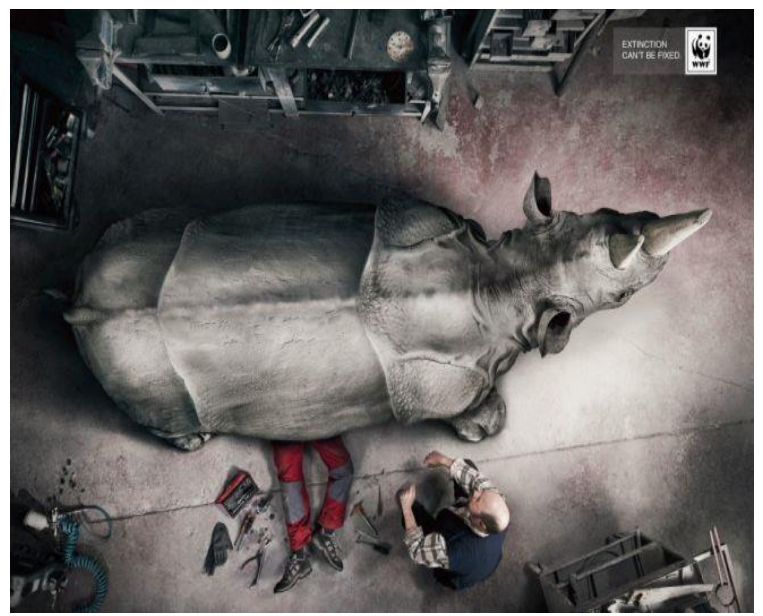

Figure 4. Actional image, the main character as the goal on poster 5

(source: https://www.adsoftheworld.com/media/print/wwf_extinction_cant_be_fixed_rhino)

Image resources of the poster are placed in photo size. Therefore, the viewers can have direct access to identify all parts of the poster. The visual representations are concerned about rhinoceros statue, a mechanic fixing the broken statue, another mechanic observing the mechanic fixing the broken belly of the rhino statue, and shapes garage equipments. All the representations are in dark-bright colour. The focus is on rhino from the bright part as the focus to the dark side.
There is a vector resulting from the sitting man's gaze to the person fixing the statue. It is not a gaze for the viewers; it is a representation of the viewers' gaze. Therefore, we can assume that the viewers are actually doing what the sitting man is doing. The gaze is represented an 'offering' action. It offers a fact or situation that, probably, most viewers' experience, namely seeing the destruction of the environment, but there is nothing that can be done about it. As an offer, the viewers are encouraged to make an interaction with the context and reach a full understanding.

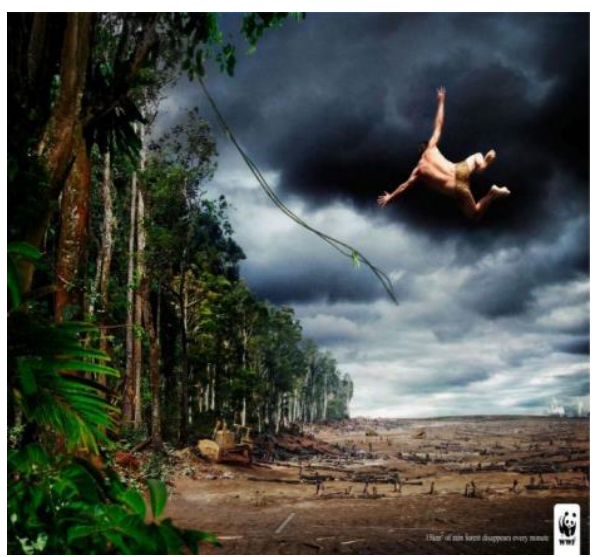

Figure 5. Given-new information on the absence of gaze on poster 2

(source: https://www.adsoftheworld.com/media/print/tarzan_0)

The analysis shows that the poster focuses on visual modality to lean on. The image is sharp. The modality resources that can be identified are flying figure, deforestation, and dark clouds. The objects are represented in bright light contrast, in realistic style. Furthermore, there are two dominant colours on the poster. There is a contrast situation between dark colour (of cloud) and bright colour (of forest).
Moreover, based on the given and new information provided by visual representation, it seems that green forest is given information. It represents the previous situation with bright colours. On the other hand, new information is represented by the upcoming situation of drained land caused by deforestation. In this sense, the green forest is the background situation, and deforestation is the foreground situation. 


\section{DISCUSSION}

This article aims to discover the interactive meanings of semiotic resources in posters on environmental campaigns using a multimodal perspective. It examines the contribution of visual and textual resources to raise people's awareness on the significance of preserving the environment for future generations. The findings have shown that the posters mostly represent multimodal interaction (textual and visual) to make people aware of current condition in environmental issues.

The transitivity analysis on the verbal text in the posters has indicated that the messages are mostly represented through the use of material process. The dominant use of the respective process represents a strong intention that the messages are mostly about the activities the readers do. It corroborates research finding done by Guijarro and Sanz (2008) stating that the use of material processes in the posters allows the readers to feel the movement of the target readers and the development of the message.

The visual process identification shows that the readers' experiences represented in the posters are mostly about interaction with the nature. The readers are the reacters/interacters. They are represented as being actively involved in their surrounding and as contributing to the protection of their environment in ways they are capable of. This representation is relevant with the mission of the posters' producer that is to raise the readers' awareness as a part of their character building program. The interaction of both parties is crucial in enhancing good character building on the part of the readers through the protection of their natural environment. The visual process identification confirms the initial research undertaken by (Ledley \& RooneyVarga, 2017).

Simultaneous with the decision to create an interaction, posters also neatly depict the intention of the producer to build a specific distance (personal, social, or impersonal). Social distance is the distance from which people, places, and things are presented, and therefore create a casual relation of physical proximity in daily interaction (Horarik, 2015). It can be identified that the posters are generally in close-up medium shots. They correspond with the 'a close social distance'. The distance is mitigated by the use of specific pronoun in its verbiage which suggests slight intimate relationship. However, the discourse is objectified through individuality (the use of 'you') to social distance (the awareness of stopping climate change). This finding appears to confirm the study conducted by Sipe (1998) which states that the text synergizes with the pictures in creating the meaning of the narrative in delivering messages. The respective posters provide the verbal and the visual which interact with each other to communicate to the readers.

The fact about verbiage which corresponds to image should be seen by the use of linguistic realization of social distance. Linguistic realization represents formality of 'style' (Kress \& Van Leeuwen, 1996). The 'personal style' of posters on environmental protection is the language of intimacy. The verbiage shows implicitness (the verbiage is limited to the image on poster), context-dependence (through the topic about climate change), and local frame of reference (through the use of personal reference 'you'). Furthermore, in terms of power, the attitude (as it is at eye-level) is representing equality, specifically on responsibility as stated by Wang (2015).

Two complementary systems enabling analysis to scrutinize information are 'theme' and 'focus' (Halliday, 1994, pp. 336-338). The theme represents speaker-oriented prominence. The focus, on the other hand, represents listener-oriented prominence. Within attitude, there are three major concepts, affect (doing with emotional responses and desires), judgement (doing with ethical evaluations of behaviour), and appreciation (doing with aesthetic dimensions of experience). Therefore, it can be concluded that the attitude of the text is judgement as, from a speakeroriented perspective, the readers are required to do things with an ethical evaluation of behaviour. Moreover, the focus of the text is parallel to the previous part which constitutes a material process.

It turns out that the visual modality on the posters constructs a specific distance. The represented figure is clearly identified as the long shot. Therefore, it corresponds with the impersonal distance, not individual distance. Impersonal distance is mitigated by the represented figure's position which puts his back before the viewers. Thus, there is no interactive process in the situation. In general situation, interactive process is situated by 'face to face' representation. The presented position correlates to the distance between people and strangers (Kress \& Van Leeuwen, 1996). Both parties are in strange situations. The viewers are busy with so many topics to contemplate, and therefore, the represented figure is also doing what he intends. Even though some posters have only a single mode (visual representation), the combination of images creates the interplay of various semiotic resources for the creation of intended meaning at different levels (Bedi, 2019).

Regarding the image position, poster 3 is also worth discussing. It is clearly seen that the images are placed in photo size (centre). Moreover, the images are situated in sharp focus with stylish style. It shows that the viewers are directly provided by the objects. The object is, however, focused only on a single object, namely the fish with the panda's head. Generally, the main colour of the poster is somewhat dark by reflecting bright light from the sun over the water.

Regarding actional issue, a poster combines verbal-visual representation. In the text representation, the poster is directly making a statement. The expression is structured in a full formal sentence; subject and verb. There is no personal pronoun which means it is not about a human's role but about the situation or setting. The expression, indeed, is not related to the whole visual representation. The 'extinction' refers to the broken rhino; therefore, the verbal-visual relation is subordinate. That is to say, the 
picture is subordinate to the text. The use of material process has, therefore, established a fact that the text represents expansion. As the text is more general than the visual, it is categorized as expansion-elaborationexemplification. In an elaboration relationship, the meaning is realized by the direct address in the text. The addressee of the text is not in the form of a personal pronoun, but the situation being put as a subject. The text is used a represented event (extinction) in the nonlinguistic experience. The extinction is an exact word to depict a reality, not an individual mental state.

In terms of specific distance, the visual representation is taken in a long shot. The viewers are imagined to observe the reality from the top part to represent impersonal distance. The distance shows that the viewers are seemingly strange entities in this issue. Putting a party at the top view also represents an unequal relationship. The viewers are considered to be more powerful than the parties who are fixing the situation. Even more, the viewers are the parties who do nothing to fix the situation, except merely seeing and witnessing it. Therefore, the assumption is that the attitude of the poster is defining involvement (at eye level representation), as well as an unequal power relation.

The involvement comes from the image presentation in horizontal dimension. As stated previously, the poster attempts to make the viewers aware that they, during the time, see the reality from the top part of the building. They are doing nothing to fix the situation. They are seeing other parties fixing the problems. However, as represented by the textual representation, the extinction is a reality that cannot be fixed. The involvement of attempting an improvement of the situation is the viewers' responsibility.

The posters, therefore, have a positive moral load. The lexical choice used in the poster suggests that the value is inscribed. There is an evaluative noun which is 'extinction'. It is a verb choice strengthening the visual representation that a fixing process is useless, as environmental extinctions can never be fixed. It seems to reflect the intention to raise readers' awareness on environmental issues. This finding, therefore, proves that multimodal resources are not only intended to improve literacy (Torr, 2004; Tulk, 2005), but also to serve significant implications for pedagogy and social awareness (Mavers, 2004).

\section{CONCLUSION}

In summary, the potential meanings of posters have different methods of making connections between the viewers and the producers. The apprehension, however, of multimodal resources can uncover direct juxtapositions of visual and textual modes. The analysis shows that five posters have certain patterns that involve varied interpretations. Moreover, some posters only lean on one mode, but the interaction of the specific mode is complex.
In relation to verbal representation, the use of material process is dominant. It implies that the readers are considered to have ability to feel their movement and the development of the message. Furthermore, material process also represents a strong intention that the focus is mostly about readers' activity.

The readers are reactors/interacters. It is related to the situation where the readers are represented as being actively involved in environmental protection. It is relevant to mission about raising the readers' awareness about the respective issues. The interaction between visual representation and readers' interpretation is necessary to build noble character on the protection of natural environment.

Most posters are generally in close-up medium shots. The style corresponds with close social distance related to casual relation of physical proximity in daily interaction. The distance is implemented by the use of specific pronoun, namely 'you'. The discourse is objectified through individuality (the use of 'you') to social distance (the awareness of stopping climate change). The visual and verbal representations are producing the narrative of intended messages.

The verbal representations in the posters are identified as personal style. It focuses on implicitness, context-dependence, and local frame of reference. The personal style is also showing equal responsibility on a specific issue. Within attitude, the text is talking about judgement as the readers are required to do things with ethical evaluation of behaviour.

In the context of visual representation, the gaze that does not generate a vector between the eye lines of the viewers means a specific meaning. As the represented object does not look directly at the viewers but gaze away, it can be considered as an offer. The poster attempts to 'offer' something. An 'offer' is realized by offering information. The information will initiate the interactivity of text-image relationship.

It is also a situation that it is not a gaze for the viewers but it is a representation of the viewers' gaze. So, it may be assumed that the viewers are actually doing what the represented object is doing. The gaze is represented an 'offering' action. It offers a fact that, probably, most viewers' experience the thing but there is nothing that can be done about it. As an offer, the viewers are encouraged to make an interaction with the context and reach a full understanding.

The focus of the image is mostly sharp. Therefore, it is easy to identify the object. In some posters, the visual representation is colourful, so that it represents more than one colour in the poster. There is no, to be noticed, living object to see. Therefore, it is not relevant to talk about contact produced by gazing of a living object. It is more relevant to analyze the contact based on the object itself.

Regarding the poster focusing only on visual modality, the image is definitely sharp. The objects are represented in bright light contrast, in realistic style. Furthermore, there are two dominant colours on the poster. There is a contrast situation between dark colour 
(of cloud) and bright colour (of forest). It represents the previous situation with bright colours. On the other hand, new information is represented by the upcoming situation. In this sense, the bright representation is the background situation, and the dark representation is the foreground situation.

The analyses indicate that multimodal resources have potential meaning. Therefore, the posters can have a significant contribution to environmental education. Education is a fundamental aspect to promote environmental sustainability. By employing multimodal resources which use a personal-social distance, the individual thinking system is activated. It might result in societal change. It is hoped that the symbolic comprehension of multimodal resources on the part of individuals will build their character through thinking about these multimodal resources, discovering the intended messages, and behaving as the resources instruct. At the end of the day, the character building process will be effectively activated within the individuals' minds pertaining to environmental issues.

\section{REFERENCES}

Barthes, R. (1967). Elements of semiology. New York: Hill \& Wang.

Bedi, N. K. (2019). Analysing the poster of the reader: A multimodal perspective. Language in India, 19(1), 159-167.

Bezemer, J., \& Kress, G. (2008). Writing in multimodal texts: A social semiotic account of design for learning. Written Communication, 25(1), 166175. doi: $10.1177 / 0741088307313177$

Birdwhistell, R. (1952). Introduction to kinesics: An annotation system for analysis of body motion and gesture. Lousville, KY: University of Lousville.

Goffman, E. (1959). The presentation of self in everyday life. New York: Doubleday.

Guijarro, J. M., \& Sanz, M. J. P. (2008). Compositional, interpersonal and representational meanings in a children's narrative: A multimodal discourse analysis. Journal of Pragmatics, 40, 1601-1619. doi: 10.1016/j.pragma.2008.04.019

Hall, E. T. (1959). The silent language. Garden City. NY: Doubleday.

Halliday, M. A. K. (1994). An introduction to functional grammar (2nd edn). London: Edward Arnold.

Halliday, M. A. K. (2001). An Introduction to functional grammar. Beijing: Foreign Language Teaching and Research Press.

Horarik, M. K. (2015). Interacting with the multimodal text: reflection on image and verbiage in ArtExpress. Visual Communication. 3(1), 5-26. doi: $10.1177 / 1470357204039596$

Howe, C. (2009). The role of education as a tool for environmental conservation and sustainable development (Unpublished doctoral dissertation). Imperial College London.

Jewitt, C. (2009) An introduction to multimodality. In C. Jewitt (Ed.) The Routledge handbook of multimodal analysis (pp. 14-27). Oxon: Routledge.

Kress, G. (2011). Literacy in the new media age. New York: Routledge.

Kress, G., \& Van Leeuwen T. (1996). Reading images: the grammar of visual design. New York: Routledge.

Ledley, S. T., \& Rooney-Varga, J. (2017). Addressing climate change through education. London: Oxford Research Encyclopaedia of Environmental Science.

Martinec, R., \& Salway, A. (2005). A system for imagetext relations in new (and old) media. Visual Communication, 4(3), 337-371. doi: $10.1177 / 1470357205055928$

Mavers, D. E. (2004). Multimodal design: the semiotic resources of children's graphic representation (Unpublished doctoral dissertation). Institute of Education, University of London, London, UK.

Pike, K. (1954). Language in relation to a unified theory of the structure of human behaviour. Glendale: Summer Institute of Linguistics.

Ruesch, J., \& Bateson, G. (1951). Communication: The social matrix of psychiatry. London: Transaction Publishers.

Sipe, R. L. (1998). How picture books work: A semiotically framed theory of text-picture relation. Children's Literature in Education, 29(2), 97-108.

Torr, J. (2004). Talking about picture books: The influence of maternal education on four-year-old children's talk with mothers and pre-school teachers. Journal of Early Childhood Literacy, 4(2), 181-210. doi: 10.1177/1468798404044515

Tulk, S. (2005). Reading picture books is serious fun. English Teaching: Practice and Critique, 4(2), 89-95.

Wang, Q. (2015). A case study on college English teacher's non-verbal behaviours under the setting of multimodality. International Journal of English Language Teaching. 43(3), 21-31. doi:10.13189/ujer.2015.030801

Webber, J. (2006). Sartre's theory of character. European Journal of Philosophy, 14(1), 94-116. doi: 10.1111/j.1468-0378.2006.00245.x

Williams, R. D. (2017). An assessment of environmental literacy among Oklahoma Public High School students and the factors affecting students' environmental literacy (Unpublished master's thesis). Harvard University, Massachusetts, US. 